\title{
Phenolic Wastewater TREATMENT USING ACTIVATED Carbon in a Three Phase FLUIDIZED-BED REACTOR
}

\section{Pratarn Wongsarivej* and Pornsiri Tongprem}

\author{
National Nanotechnology Center, Thailand Science Park, \\ Klong Luang, Pathumthani, Thailand 12120
}

Email: pratarn@nanotec.or.th*,pornsiri@nanotec.or.th

\section{ABSTRACT}

Phenolic wastewater treatment by activated carbon in a laboratory scale three phase fluidized-bed reactor was investigated. The reactor with effective volume of $272 \mathrm{ml}, 300 \mathrm{~mm}$ in height and $40 \mathrm{~mm}$ in diameter was made from transparent acrylic that allowed to observe the phenomena occurring inside. Aqueous solution containing $10 \mathrm{mg} / \mathrm{l}$ of phenol and air were used as representative agents that were continuously fed to the reactor at a constant flow rate of 1 and $2 \mathrm{l} / \mathrm{min}$ with co-current and up-flow, respectively. Comparison of the phenolic adsorption under five different adsorbents: (a) fresh GAC, (b) $1^{\text {st }}$ reused GAC, (c) fresh Fe/GAC, (d) $1^{\text {st }}$ reused Fe/GAC, and (e) $2^{\text {nd }}$ reused Fe/GAC, have been carried out. The phenolic wastewater was re-circulated through the reactor and its concentration was measured with respect to time. The experimental adsorption results revealed that both fresh GAC and Fe/GAC gave the better results than reused GAC and reused Fe/GAC, respectively. The adsorption in all cases of GAC and Fe/GAC would follow pseudo-second order kinetic.

\section{KEYWORDS}

phenol, wastewater, activated carbon, three phase fluidized-bed reactor 


\section{Introduction}

Phenol is one of important starting and/or intermediate materials in various industrial processes. Phenol is known or suspected to be carcinogens, it is well known for its high stability and toxicity. It has been declared to be a hazardous pollutant even at the very low concentration [1]. It can damage the skin and other tissues of the human and animals. When digested, phenol-containing liquids could also lead to liver damages, dark urine and irregular heart beats. Therefore, the treatment of phenolic wastewater is considerable importance in environmental protection. Researchers have been attempted to use many technologies for phenolic wastewater treatment, for example biological treatment [2], chemical precipitation or oxidation [3], and ion exchange [4]. However, there are few suitable processes for this high toxicity effluent with reasonable costs. Adsorption by granular activated carbons and its derivative is one of the conventional process representing an environmentally friendly alternative of phenolic treatment [5]. The three phase fluidized-bed reactor has received considerable attention and wide utilization in wastewater treatment due to several advantages. For example, first, this reactor has a more intensive contact between gas, liquid, and solid phase causing high mass transfer, high reaction rate, and small external mass transfer resistance between solid and liquid phase. Second, it could eliminate the operating problems such as bed clogging and high pressure drop, which occur in packed-bed operations. Third, it is a high efficient, simple, stable and economical operation compared to other reactor configurations [6]. In this research, the removal of phenol is investigated under the adsorption process with and without impregnation of Fe nanoparticles using a laboratory scale three phase fluidized-bed reactor. Adsorption results of fresh and reused activated carbons, GAC, including fresh and reused Fe catalysts supported on GAC, Fe/GAC, are also examined.

\section{Experiments}

\subsection{Catalyst preparation}

The test granulated coconut shell activated carbons were purchased from Carbokarn (Thailand) Co., Ltd. GAC was sieved to obtain in the size range of $0.4-2.0 \mathrm{~mm}$ particle diameter. Fe/GAC was prepared following the incipient wetness impregnation technique. The classified GAC was heated and held at $473 \mathrm{~K}$ for $4 \mathrm{hrs}$ to eliminate their impurities, then impregnated with a solution of $\mathrm{Fe}(\mathrm{NO} 3) 3 \bullet 9 \mathrm{H} 2 \mathrm{O}$ to yield $5 \% \mathrm{w} / \mathrm{w}$ of $\mathrm{Fe}$. In order to obtain this \%w/w, $0.5 \mathrm{ml}$ of iron solution was impregnated on $1 \mathrm{~g}$ of GAC at $353 \mathrm{~K}$. After impregnation, the samples were dried overnight at $353 \mathrm{~K}$ and subsequently calcined at $773 \mathrm{~K}$ under $0.8 \mathrm{l} / \mathrm{min}$ of nitrogen flow for $5 \mathrm{hrs}$.

\subsection{Characterization}

Following the Brunauer-Emmett-Teller, BET adsorption method, the specific surface area and porosities of the activated carbons and catalysts were measured via $\mathrm{N}_{2}$ adsorption-desorption isotherms. Test materials were measured at $77 \mathrm{~K}$ using an automatic adsorption apparatus (BELSORP 28, BEL Japan Inc.). The morphological structures of the activated carbons and the Fe catalysts were characterized by Scanning electron micro scope, SEM (Hitachi S-3400N) at the National Nanotechnology Center.

\subsection{Apparatus and procedure}

The reactor with effective volume of $272 \mathrm{ml}$ was made from transparent acrylic that allowed to observe the phenomena occurring inside. The outside diameter and height of the reactor were 40 and $300 \mathrm{~mm}$, respectively. Aqueous solution of phenol and air were used as representative agents that were continuously fed to the reactor at a constant flow rate of 1 and $2 \mathrm{l} / \mathrm{min}$ with co-current and up-flow, respectively. Phenolic stock solution was prepared early by diluting $10 \mathrm{~g}$ of phenol crystal from Fisher Scientific with 1 liter of distilled water. Then, the aqueous solution containing $10 \mathrm{mg} / \mathrm{l}$ of phenol was prepared by mixing $5994 \mathrm{ml}$ of distilled water with $6 \mathrm{ml}$ of phenolic stock solution. The 6 liters of phenol was tested with a catalyst concentration of 0.83 $\mathrm{g}_{\mathrm{cat}} / \mathrm{l}_{\text {phenol}}$. The aqueous temperature in the tank was constantly measured and controlled at $303 \mathrm{~K}$ using a thermocouple and a cooler. Comparison of the phenolic 
adsorption under five different adsorbents: (a) fresh GAC, (b) $1^{\text {st }}$ reused GAC, (c) fresh $\mathrm{Fe} / \mathrm{GAC}$, (d) $1^{\text {st }}$ reused Fe/GAC, and (e) $2^{\text {nd }}$ reused Fe/GAC, were carried out. In addition, the ozone generator was switched off in all experiments but would setting on in case of enhanced with ozone in next articles.

Figure 1

Schematic diagram of experimental apparatus:

1. hold-up tank

2. liquid pump

3. ball valve

4. liquid flow meter

5. air flow meter

6. ozone generator

7. air pump

8. three phase

fluidized-bed reactor

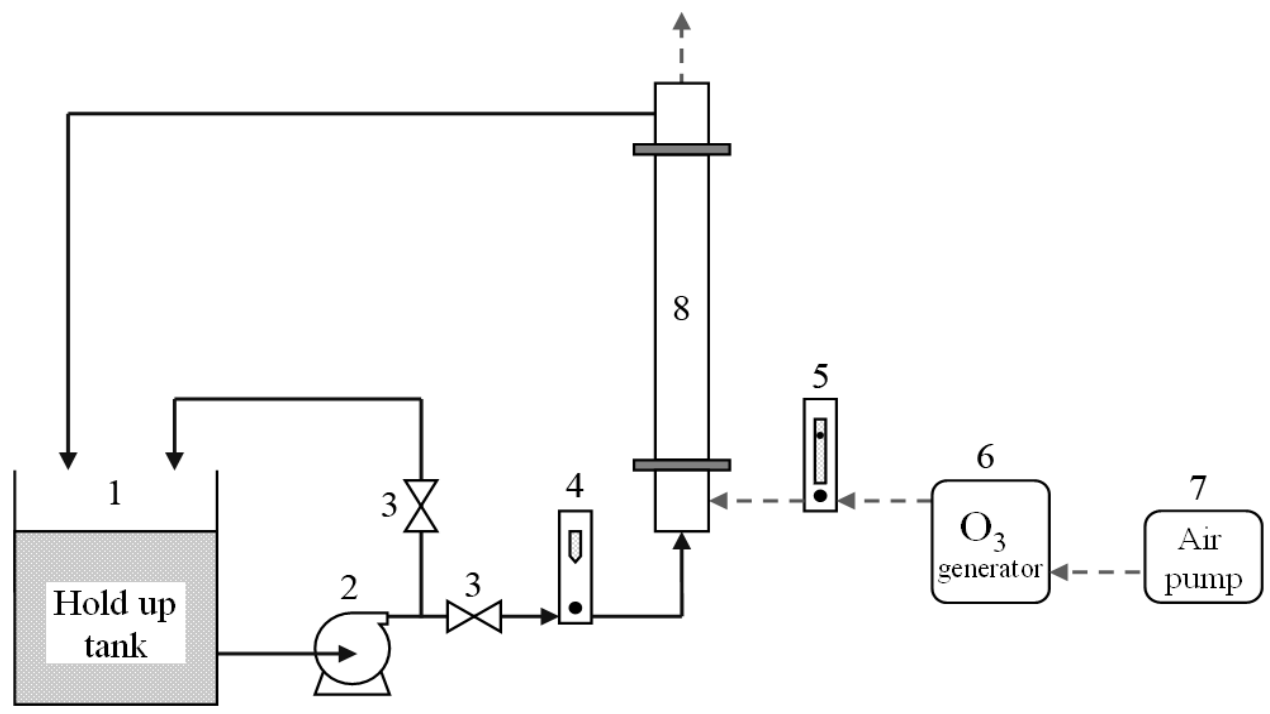

Figure 2

Fluidized-bed reactor

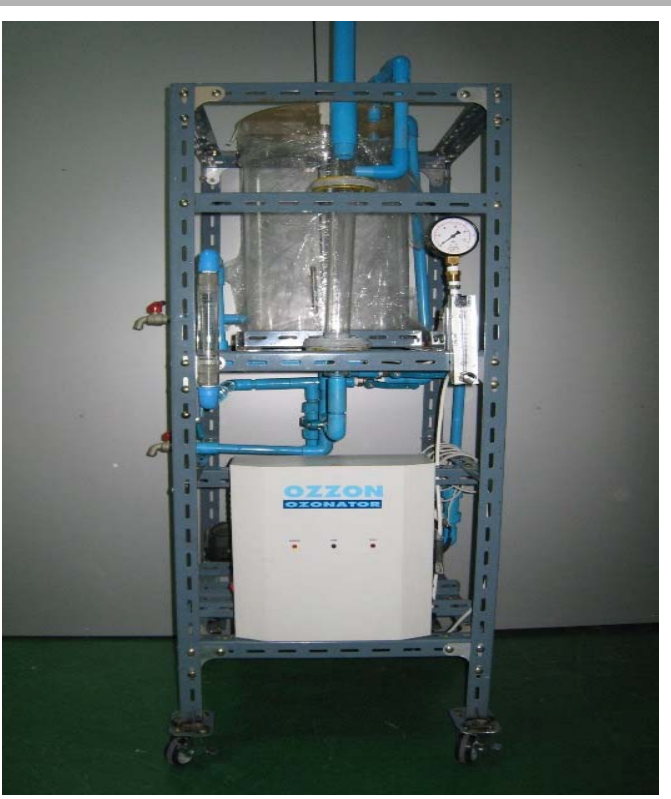

\subsection{Chemical analysis}

The progress of the reaction was followed by periodically taking liquid samples from the reactor and immediately analyzed after filtration through $0.45 \mu \mathrm{m}$ nylon filter. Phenol was identified and quantified by High performance liquid chromatography (HPLC, Shimadzu, LC-20A Series) with a diode array detector at wavelengths of 210 and $254 \mathrm{~nm}$. The $5 \mu \mathrm{m}$ of C18 column (Inertsil ODS-3, $25 \mathrm{~cm}$ in length, $4.6 \mathrm{~mm}$ in diameter) was used as stationary phase. The mixture of $4 \mathrm{mM}$ aqueous sulfuric solution and $20 \% \mathrm{v} / \mathrm{v}$ aqueous acetonitrile solution was used as mobile phase at 1.5 $\mathrm{ml} / \mathrm{min}$. 


\subsection{Analyzed data}

The adsorption data were analyzed in term of the pseudo-first order and pseudosecond order kinetics as follows

$$
\begin{aligned}
& \log \left(q_{e}-q_{t}\right)=\log q_{e}-\frac{k_{1} t}{2.303} \\
& \frac{t}{q_{t}}=\frac{1}{k_{2} q_{e}^{2}}+\frac{t}{q_{e}}
\end{aligned}
$$

where $q_{\mathrm{e}}$ and $q_{t}$ are adsorption ability at equilibrium and at time, $\mathrm{t}\left(\mathrm{mg}_{\text {phenol }} / \mathrm{g}_{\text {adsorbent }}\right)$ respectively; $k_{1}$ and $k_{2}$ are first and second order rate constants, respectively.

\section{Results and Discussion}

The specific surface area and porosity of the GAC and Fe/GAC are shown in Table 1. The surface area of GAC with Fe catalyst decreases after iron loading. GAC shows slightly larger total pore and micropore volume than Fe/GAC because it has smaller average micropore size than Fe/GAC. However, GAC has slightly higher BET area than Fe/GAC of $7 \%$. To clearly understand the coating, the morphology of GAC and Fe/GAC were determined by scanning electron micro scope (see Fig. 3 and 4), respectively. From the figures, they can be seen that Fe dispersedly coated on the surface of activated carbons. It should be noted that the porosity of the obtained Fe/GAC is significantly affected by the impregnation.

\begin{tabular}{ccccccc}
\hline Sample & $\begin{array}{c}\text { BET } \\
\text { surface } \\
\text { area } \\
\left(\mathrm{m}^{2} \mathrm{~g}^{-1}\right)\end{array}$ & Pore size & $\begin{array}{c}\text { Total pore } \\
\text { volume } \\
\left(\mathrm{cm}^{3} \mathrm{~g}^{-1}\right)\end{array}$ & $\begin{array}{c}\text { Average } \\
\text { pore } \\
\text { diameter } \\
(\mathrm{nm})\end{array}$ & $\begin{array}{c}\text { Micropore } \\
\text { volume } \\
\left(\mathrm{cm}^{3} \mathrm{~g}^{-1}\right)\end{array}$ & $\begin{array}{c}\text { Average } \\
\text { Micropore } \\
\text { diameter } \\
(\mathrm{nm})\end{array}$ \\
\hline GAC & $1154 \pm 22$ & micropore & $0.49 \pm 0.01$ & $1.4 \pm 0.04$ & $0.49 \pm 0.01$ & $0.6 \pm 0.01$ \\
\hline Fe/Gac & $1081 \pm 22$ & micropore & $0.46 \pm 0.01$ & $1.7 \pm 0.04$ & $0.46 \pm 0.01$ & $0.7 \pm 0.0$. \\
\hline
\end{tabular}

Table 1

The porous characteristics of $\mathrm{GAC}$ and $\mathrm{Fe} / \mathrm{GAC}$

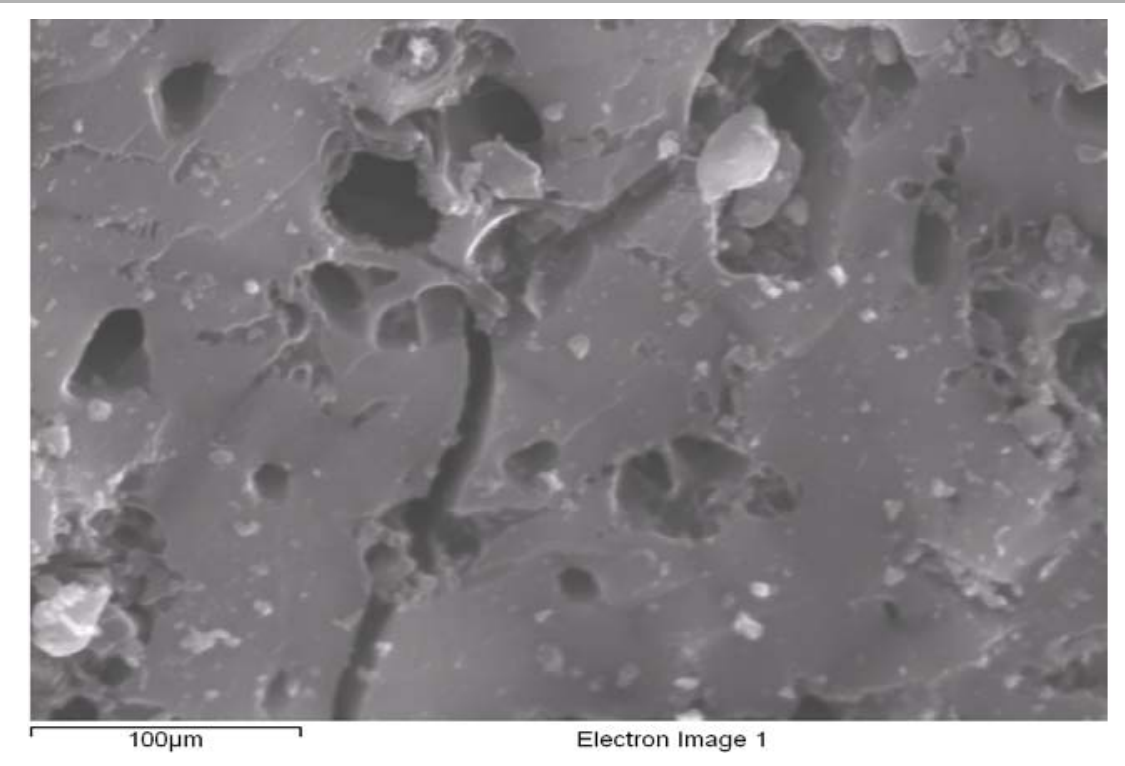

Figure 3

Scanning electron micro scope image of GAC 
Figure 4

Scanning electron micro scope image of $\mathrm{Fe} / \mathrm{GAC}$

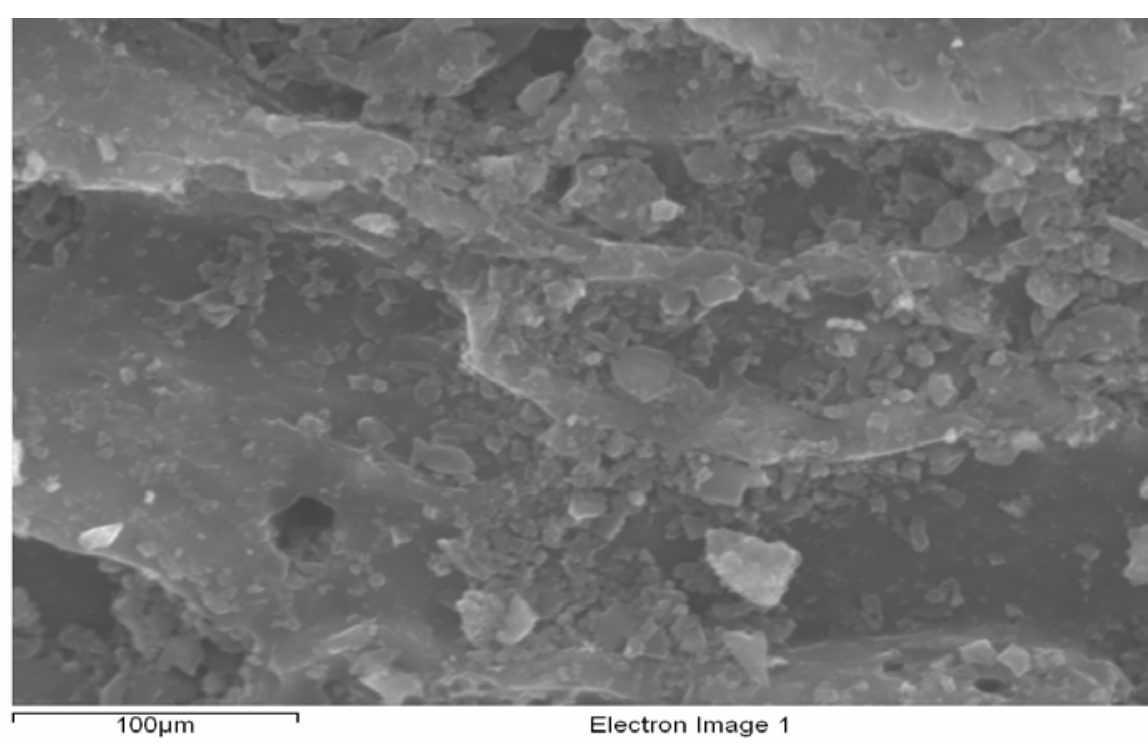

The adsorption of phenol from the initial concentration of $10 \mathrm{mg} / \mathrm{l}$ by treatment with a laboratory scale fluidized-bed reactor under five different adsorbents: (a) fresh GAC, (b) $1^{\text {st }}$ reused GAC, (c) fresh Fe/GAC, (d) $1^{\text {st }}$ reused Fe/GAC, and (e) $2^{\text {nd }}$ reused $\mathrm{Fe} / \mathrm{GAC}$ are shown in Fig. 5. The representative information is the average value of triplicated data in each experimental condition

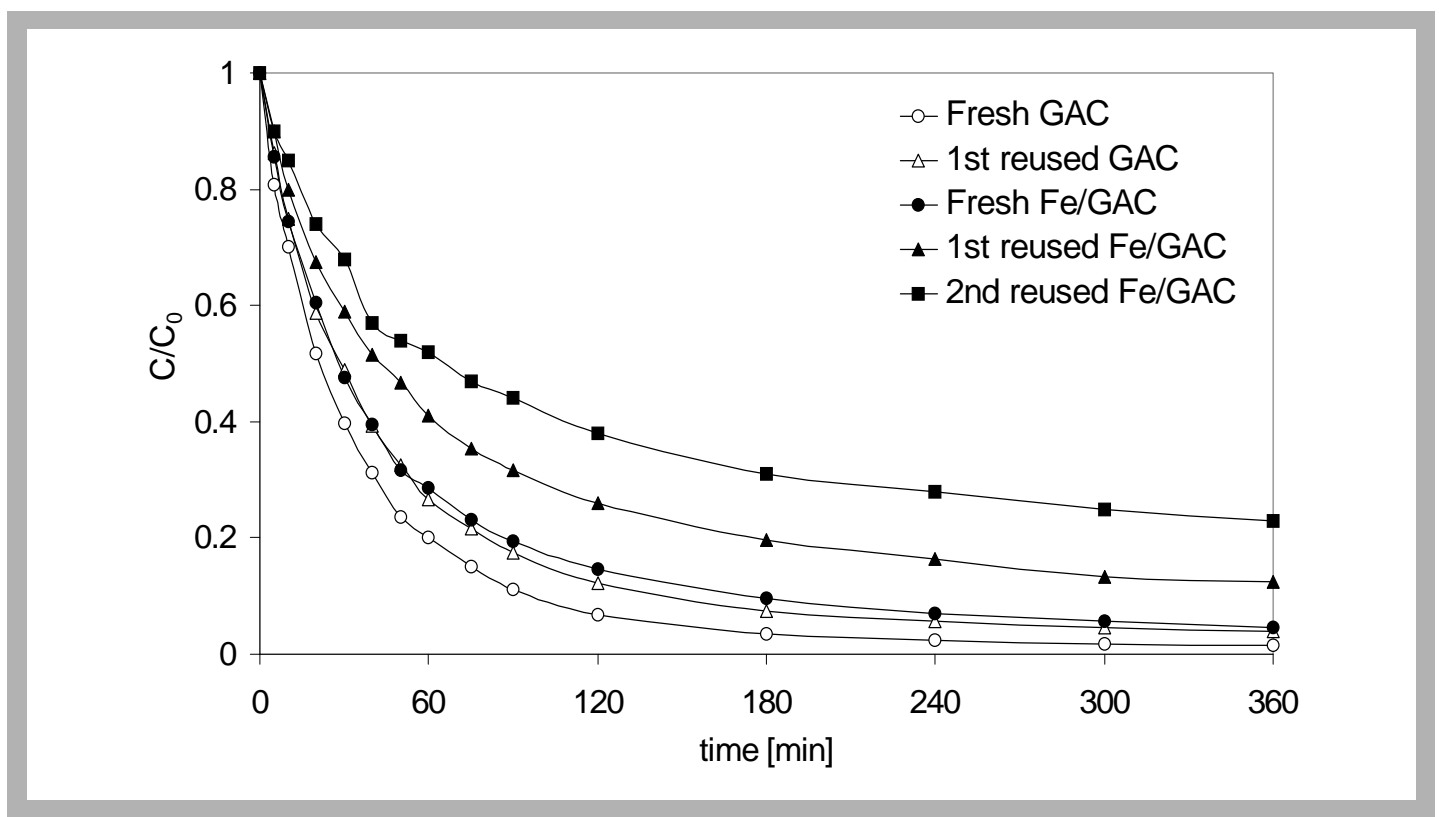

From Fig. 5, when comparing the adsorption performance of phenol in any cases of Fe/GAC, fresh Fe/GAC shows the best result while $1^{\text {st }}$ reused Fe/GAC significantly adsorbs phenol better than $2^{\text {nd }}$ reused Fe/GAC. Similarly, fresh GAC adsorbs phenol better than $1^{\text {st }}$ reused GAC. Fresh GAC has higher adsorption ability than reused GAC because of the decreasing and leaching of active adsorption surface area. Substantially, GAC adsorbs phenol faster than Fe/GAC in all cases. As a result of Fe molecules blocking some part of pore size of activated carbons, the pore volume and adsorption performance of Fe/GAC decrease accordingly.

The adsorption ability of phenol as a function of time of GAC and Fe/GAC is shown in Fig. 6. It revealed that fresh GAC gives the best result when comparing with the other cases. After the 360 minutes of experiment, the adsorption equilibriums were reached. 


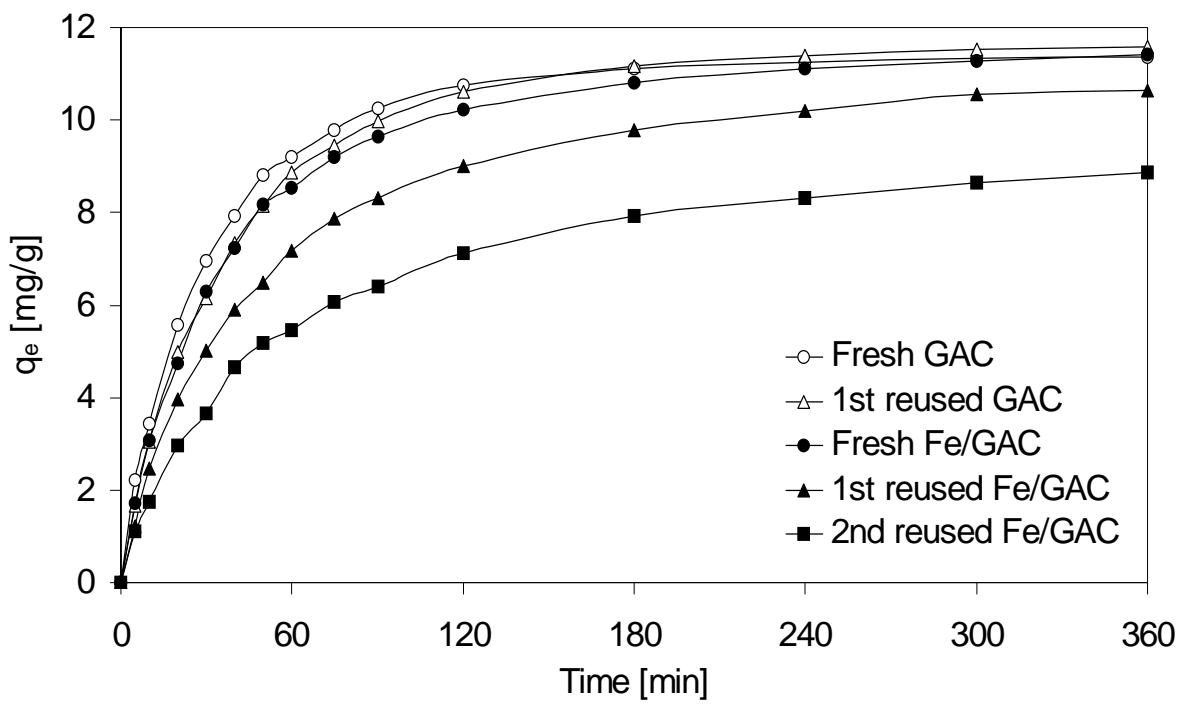

Figure 6 Adsorption ability of phenol as a function of time of GAC and Fe/GAC

Various kinetic models including the pseudo-first order and pseudo-second order were tested for the experimental data to elucidate the adsorption mechanism. In case of the firstorder rate equation of GAC and Fe/GAC, the values of $k_{1}$ and $q_{e}$ were calculated from the slope and intercept of the plot of $\log \left(q_{\mathrm{e}}-q_{t}\right)$ versus $t$ (see Fig. 7). It was found that the correlation coefficients for the pseudo first-order model were lower than that of the pseudo second-order model. These parameters are summarized in Table 2. This implies that the adsorption process does not follow first-order kinetic.

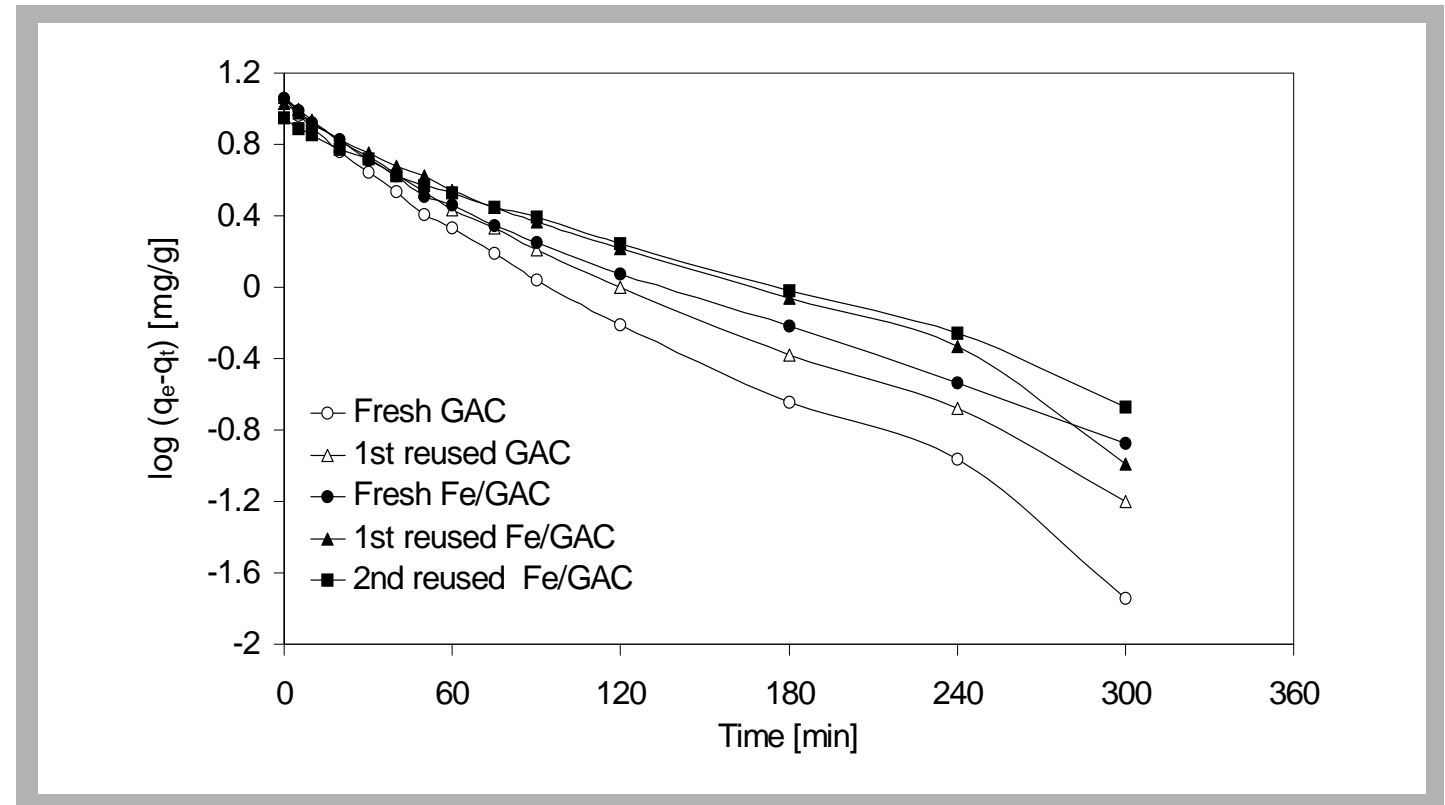

Figure 7

Pseudo-first order of GAC and Fe/GAC

In case of the second-order rate equation of GAC and Fe/GAC, the values of $k_{2}$ and $q_{e}$ were calculated from the plot of $t / q_{t}$ against $t$ (see Fig. 8 and Table 2). The calculated $q_{e}$ values agree well with experimental $q_{e}$ values. The correlation coefficients for the pseudosecond order kinetic plots were very high. These results suggested that the appropriate adsorption kinetic of both GAC and Fe/GAC would follow pseudo-second order kinetic. 
Figure 8

Pseudo-second order of GAC and $\mathrm{Fe} / \mathrm{GAC}$

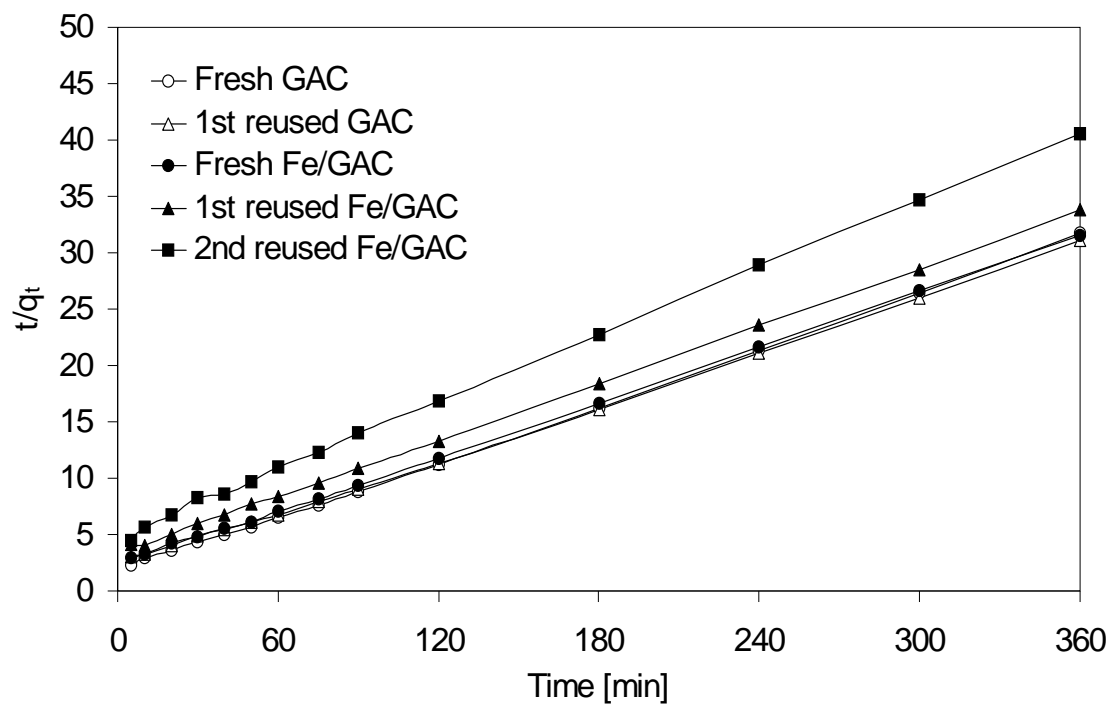

Pseudo-first order Pseudo-second order
Table 2

Experimental and calculated adsorption ability rate constant and R-square of GAC and Fe/GAC

\begin{tabular}{|c|c|c|c|c|c|c|c|}
\hline \multirow{2}{*}{ Sample } & \multirow{2}{*}{$\mathrm{q}_{\mathrm{e}}(\mathrm{exp})$} & \multicolumn{3}{|c|}{ Pseudo-first order } & \multicolumn{3}{|c|}{ Pseudo-second order } \\
\hline & & $\mathrm{q}_{\mathrm{e}}$ (cal) & $\mathrm{k}_{1}$ & $\mathrm{R}^{2}$ & $\mathrm{q}_{\mathrm{e}}(\mathrm{cal})$ & $\mathrm{k}_{2}$ & $\mathrm{R}^{2}$ \\
\hline Fresh GAC & 11.35 & 8.31 & 0.0200 & 0.9870 & 12.15 & 0.0040 & 0.9992 \\
\hline $1^{\text {st }}$ reused GAC & 11.60 & 8.86 & 0.0166 & 0.9885 & 12.67 & 0.0028 & 0.9991 \\
\hline Fresh Fe/GAC & 11.41 & 8.11 & 0.0143 & 0.9789 & 12.39 & 0.0029 & 0.9996 \\
\hline $1^{\text {st }}$ reused Fe/GAC & 10.65 & 9.02 & 0.0140 & 0.9837 & 11.92 & 0.0021 & 0.9998 \\
\hline $2^{\text {nd }}$ reused Fe/GAC & 8.87 & 7.43 & 0.0117 & 0.9909 & 10.00 & 0.0021 & 0.9994 \\
\hline
\end{tabular}

It should be noted that, fresh activated carbon has higher adsorption ability than doped activated carbon. However, in actual waste treatment, using fresh activated carbon in each batch of waste treatment is not practical. The phenol removal from ozone by ozonation is an alternative due to the lower cost. In the past batch after using fresh activated carbon, the efficiency of the adsorption kinetic decreases while the effect of ozonation increases. Ozonation exhibits a stronger effect when activated carbon enhanced with a noble metal, i.e. $\mathrm{Fe}$ in this research. The choice is between the fast removal in a short period (only GAC), or slightly fast removal during a long period, (Fe/GAC enhanced with $\mathrm{O}_{3}$ ). The phenolic wastewater treatment in case of enhanced with $\mathrm{O}_{3}$ would be presented in next articles.

\section{Conclusions}

Adsorption of phenolic wastewater using activated carbons and Fe catalysts has been examined. The obtained conclusions are as follows:

1) The surface area of Fe/GAC decreases after iron loading. As a result of Fe molecules blocking some part of pore size of activated carbons, the pore volume and adsorption performance of Fe/GAC decrease accordingly.

2) Activated carbons adsorb phenol faster than Fe/GAC.

3) When comparing the adsorption performance of phenol between fresh and reused GAC or between fresh and reused Fe/GAC, it was found that both fresh GAC and Fe/GAC 
gave the better results than reused GAC and reused Fe/GAC, respectively. This result is due to the decreasing and leaching of active adsorption surface area.

4) The adsorption in all cases of GAC and Fe/GAC would follow pseudo-second order kinetic.

\section{ACKNOWLEDGEMENT}

The authors received full support from the National Nanotechnology Center (NANOTEC), and the National Science and Technology Development Agency (NSTDA). This research is a collaboration of NANOTEC and Chulalongkorn University (CU). The excellent facilities were supported from the National Metal and Materials Technology Center (MTEC) and CU. The authors would like to respectfully express thanks to Prof. Wiwut Tanthapanichakoon for his great advice and deep discussions. 


\section{REFERENCES}

[1] J. A. Zazo, J. A. Casas, A. F. Mohedano and J. J. Rodriguez, "Catalytic wet peroxide oxidation of phenol with a Fe/active carbon catalyst," Applied Catalysis B: Environmental, vol. 65, no. 3-4, pp. 261-268, 2006.

[2] M. S. Khehra, H. S. Saini, D. K. Sharm, B. S. Chadha and S. S. Chimni, "Biodegradation of azo dye C.I. Acid Red 88 by an anoxic-aerobic sequential bioreactor," Dyes and Pigments, vol. 70, no. 1, pp. 1-7, 2006.

[3] M. S. Lucas, A. A. Dias, A. Sampaio, C. Amaral and J. A. Peres, "Degradation of a textile reactive azo dye by a combined chemical-biological process: Fenton's reagent yeast," Water Research, vol. 41, no. 5, pp. 1103-1109, 2007.

[4] S. Raghu and A. C. Basha, "Chemical or electrochemical techniques, followed by ion exchange, for recycle of textile dye wastewater," Journal of Hazardous Materials, vol. 149, no. 2, pp. 324-330, 2007.

[5] S. Wang and Z. H. Zhu, "Effects of acidic treatment of activated carbons on dye adsorption," Dyes and Pigments, vol. 75, no. 2, pp. 306-314, 2007.

[6] D. Mowla and M. Ahmadi, "Theoretical and experimental investigation of biodegradation of hydrocarbon polluted water in a three phase fluidized-bed bioreactor with PVC biofilm support," Biochemical Engineering Journal, vol. 36, no. 2, pp. 147-156, 2007. 